\title{
Effects of Hematopoietic Stem Cells on Liver Cirrhosis of Albino Rats
}

\author{
NEHAL A. BAHAA EL-DIN, M.Sc.*; YOUSSEF HUSSEIN, M.D.*; MANAL M. MORSY, M.D.* and \\ NERMIN RAAFAT, M.D.** \\ The Departments of Human Anatomy \& Embryology* and Medical Biochemistry \& Molecular Biology**, \\ Faculty of Medicine, Zagazig University, Egypt
}

\begin{abstract}
Background: Liver cirrhosis is a common serious disease in Egypt due to high incidence rate of infectious liver diseases; hepatitis. Application of Hematopoietic Stem Cells (HSCs) may provide a hope for patients with liver cirrhosis as it is not only safe but also to avoid hazardous complications and immunosuppressive drug following liver transplantation.
\end{abstract}

Aim of Study: Evaluation of the effects of CD34 ${ }^{+}$hematopoietic stem cells in regeneration of hepatic tissue as a new therapy for cirrhotic liver.

Material and Methods: Forty five male albino rats were divided into four groups: Control group: Include 18 rats injected with olive oil subcutaneously, (carbon tetrachloride treated group): 9 rats received carbon tetrachloride subcutaneously, (carbon tetrachloride/hematopiotic stem cells treated group): 9 rats injected with hematopiotic stem cells after induction of liver cirrhosis by carbon tetrachloride and (carbon tetrachloride/fibroblast treated group): 9 rats injected with fibroblast cells after carbon tetrachloride induced liver cirrhosis. For histological and biochemical study of liver and blood samples were taken from all rats.

Results: Rats of carbon tetrachloride treated group \& carbon tetrachloride/fibroblast treated group indicated significant changes in liver histological structures accompanied with significant decline of liver function tests. Injection of HSC showed marked improvement in both histological picture and biochemical profile.

Conclusion: This study indicates the effectiveness of human $\mathrm{CD} 4^{+}$hematopoietic stem cells in amelioration of $\mathrm{CCl} 4$ induced liver cirrhosis in rats. So, treatment with hematopoietic stem cells therapy can be considered a new hope for cirrhotic patients, especially in Egypt.

Key Words: Hematopioetic stem cells - Cirrhosis - Albino rats.

Correspondence to: Dr. Nehal A. Bahaa El-Din, The Department of Human Anatomy \& Embryology, Faculty of Medicine, Zagazig University, Egypt

\section{Introduction}

THE liver is the largest glandular tissue of the human body. The liver has essential and multiple functions like metabolic conversion of hazardous toxic substances, storage of carbohydrates, lipids and amino acids [1].

Cirrhosis represents the end progressive hepatic fibrosis and it is characterized by loss of the classic hepatic architecture with subsequent formation of newly regenerative nodules. Cirrhosis produces a series of complicating diseases like portal, gastrointestinal bleeding and hepatic encephalopathy [2].

In patients with late stage of cirrhosis or hepatic carcinoma, liver transplantation is considered only effective treatment but, unfortunately it has many problem as high costs, unavailable donors, operative damage and post transplantation immune rejection. In addition, transplanting liver in the long run produces many complications like chronic renal and cardiovascular failure and lympho-proliferative disorders $[3,4]$, so; there is great need for alternative therapies. Ogawa and Miyagawa [5] demonstrated that there are two types of stem cells: Adult and embryonic stem cell.

In adult stem cell research Hematopoitic Stem Cells (HSC) are preferred than embryonic not only because of their capability of extensive proliferation and differentiation into several cell types but also they have less immunocompatibility problems and less tendency of tumors formation in the recipient [6-9].

Sato et al., [10] detected the capability of differentiation of stem cells to hepatocytes after their 
inoculation into damaged rat's liver from chronic alcohol treatment. Carbon tetra chloride $\mathrm{CCl} 4$ is widely used material for induction of liver injury. Only one dose of $\mathrm{CCl} 4$ produces steatosis and centizonal necrosis while sustained administration induces hepatic cirrhosis with subsequent carcinoma $[11,12]$. So the present work aimed at detecting the possible therapeutic role of injected hematopoietic stem cells on damaged liver tissue induced by $\mathrm{CCl} 4$ in male adult albino rats.

\section{Material and Methods}

\section{Animals and ethics:}

This study was carried on forty five adult male albino rats. The weight of the rats ranged from $160-210 \mathrm{gm}$. They were bred in a light-controlled 12-h day light: 12-h dark and in a temperaturecontrolled room. They were permitted to unlimited access to food and water. The study was performed in Animal House in the Faculty of Medicine, Zagazig University during 2018. All guidelines of the experimental animal procedures were followed the Institutional Animal Care and Use Committee.

\section{CCl4-induction of liver cirrhosis in rats:}

Establishment of the liver-cirrhotic rat model, was by dissolving of $0.5 \mathrm{ml} / \mathrm{kg} \mathrm{Bwt}$ of CCl4 in the same volume of olive oil. The dose was injected subcutaneous into rats twice a week for 6 weeks. CCl4 was purchased from Sigma, St Louis, USA. The state of liver damage and cirrhosis was confirmed by blood biochemical investigations and also histological examination of the liver samples [13].

\section{Experimental design:}

Forty five adult male albino rats were allocated into four groups: Control group: Including 18 which was subdivided into two subgroup; control negative included 9 rats which were received nothing and control positive included 9 rats which were injected $0.5 \mathrm{ml} / \mathrm{kg}$ olive oil subcutaneously twice a week for 6 weeks. CCl4 group (cirrhotic group): Including 9 rats injected with $\mathrm{CCl} 4$ subcutaneously twice per weeks for 6 weeks. After 6 weeks 3 rats were sacrificed to confirm that liver cirrhosis had occurred. CCl4/HSCs treated group: Including 9 rats that were injected with $\mathrm{CCl} 4$ in the same manner like cirrhotic group then after 6 weeks, they were injected intrapertoineal with dose of 107 $\mathrm{CD} 34^{+}$cells/rat [14]. The rats will be leaved for 3 weeks after HSC injection [14]. Group IV (CCl4fibroblast treated group): Including 9 animals received carbon tetrachloride (CCl4) as cirrhotic group to induce cirrhosis plus injection of fibroblast. All the animals of the different groups were sacrificed after 9 weeks.

\section{Blood and tissue sampling:}

Three weeks after HSC or fibroblast injection, blood samples were collected from retro-orbital plexus from all groups for biochemical analysis then all rats were sacrificed. Abdominal incision was performed and the liver was immediately excised. For both histological and immunehistochemistry assessment.

\section{Histological study:}

Liver was carefully dissected, immersed in $10 \%$ formalin solution, processed for preparation of 5 ickness paraffin sections then stained with Haematoxylin and Eosin stain (H \& E), Masson's trichrome for detection of collagen fibers, Periodic Acid Schiff reaction (PAS) for detection of glycogen granules [15]

\section{Immunohistochemical analysis:}

Immunohistochemical staining by the use of antigen retrieval technique for detection of alpha smooth muscle actin ( $\alpha$-SMA) and CD34+ cells. The primary antibodies used were a monoclonal anti-CD34+ and monoclonal immunoglobulin (IgG) anti $\alpha$-SMA antibody (Sigma Biochemical, Missouri, USA) [16]

\section{Biochemical analysis:}

\section{Liver function assessment:}

Serum activities of Alanine Transferase (ALT), Aspartate Transferase (AST), Alkaline Phosphatase (ALP), serum direct and total bilirubin and serum albumin levels were detected by using kits purchased from Elitech (France). All of these parameters were assessed by spectrophometrically [17]

Reverse transcription of PCR for detection of hepatic genes:

Total RNA was obtained and isolated from hepatocytes by using Qiagen-RNeasy Mini kit. Then c-DNA was obtained via reverse-transcribed of RNA by using a Prime script RT Reagent Kit (Takara, Shiga, Japan) (Table 1) [18]

\footnotetext{
Preparation of Hematopoietic Stem Cells (HSCs):

Isolation and culture of hematopoietic stem cells:

Peripheral blood total mononuclear cells were obtained from human blood unit from blood bank. PB-CD34+ cells isolated from total mononuclear cells. Anti-coagulated human blood was diluted
} 
with PBS which contains 2mm EDTA at the ratio of $2: 3$. From this diluted sample, $35 \mathrm{ml}$ was taken, layered carefully on $16 \mathrm{ml}$ Ficoll-Paque and then centrifuged at $400 \mathrm{xg}$ rpm for $35 \mathrm{~min}$. The suspension that contain mononuclear cell was resuspended in a complete culture medium: Dulbecco's Modified Eagle's Medium (DMEM) with 2mmol/L 1glutamine, $10 \%$ Fetal Bovine Serum (FBS) and $1 \%$ penicillin-amphotericin B-streptomycin solution. Then they were incubated in 5\% humidified $\mathrm{CO} 2$ incubator at $37^{\circ} \mathrm{C}$. Preparation of the suspension that contained hematopoietic cell was done by repeated pipetting of the suspension via needles. The proper mixing of the suspension was made by vortex then centrifuged for $10 \mathrm{~min}$ at $3000 \mathrm{RPM}$. After the removal of the remaining particulates of blood, the pellet was washed with Phosphate Buffer Saline (PBS) then centrifuged for two times. The formed pellet was diluted with PBS. The collected interface cells which separated from the peripheral blood mononuclear cells were moved into another centrifuge tube with PBS wash to be centrifuged for $5 \mathrm{~min}$ at 2000RPM that repeated for two times and the supernatant was removed and the resulting cells were ready for transplantation for treated rats

\section{Characterization of HSC:}

HSC typically appear as round objects surrounded by bright halos detected by inverted microscope and by determination of $\mathrm{CD} 34^{+}$cell marker by immunohistochemical stained sections.

\section{Quantitative morphometrical study:}

Sections stained with Masson's trichrome and $\alpha$-SMA immunehistochemical reaction were used for measurements of area percentage $\%$ of collagen fibers in Masson's trichrome sections, area percentage $\%$ of $\alpha$-SMA immune reaction in $\alpha$-SMA immunohistochemical section and optical density of $\alpha$-SMA immunoreaction. The measurements were performed at magnification 400x by using Leica Q500 Image analysis computer System (Leica Q500).

\section{Statistical analysis:}

The results were mentioned as mean $\pm \mathrm{SD}$. A one-way Analysis of Variance (ANOVA) was used for comparison of means from different studied groups followed by Least SignifiCant Difference (LSD) for comparison between each two groups. Significant differences were determined when $p$ values $<0.05$. Highly significant were recorded when $p$-values $<0.001$. All statistical analyses were performed by using SPSS program, Version 19
Table (1): Gene primer sequnces.

\begin{tabular}{|c|c|c|}
\hline $\begin{array}{l}\text { Target } \\
\text { gene }\end{array}$ & Primersequence: $5^{\prime}-3^{\prime}$ & $\begin{array}{c}\text { Gene number } \\
\text { bank accession }\end{array}$ \\
\hline Albumin & $\begin{array}{l}\text { Forward: } \\
\text { TTTACGAGAAGCTTGGAGAG } \\
\text { Reverse: } \\
\text { TGTGCAGATATCAGAGTGGA }\end{array}$ & FQ210445.1 \\
\hline TGF- $\beta$ & $\begin{array}{l}\text { Forward: } \\
\text { TGCGCCTGCAGAGATTCAAG } \\
\text { Reverse: } \\
\text { AGGTAACGCCAGGAATTGTTGCTA }\end{array}$ & NM_021578.2 \\
\hline GAPDH & $\begin{array}{l}\text { Forward: } \\
\text { CACCCTGTTGCTGTAGCCATATTC } \\
\text { Reverse: } \\
\text { GACATCAAGAAGGTGGTGAAGCAG }\end{array}$ & XR_598347.1 \\
\hline
\end{tabular}

\section{Results}

Histological and immunohistochemical results:

Haematoxylin \& Eosin stained sections: H \& E stained liver sections of control group revealed classic characteristic appearance of hepatic lobules which consisted of cords of hepatocyte radiating from central vein. Portal area was present at the corner of lobule containing branches of portal vein, hepatic artery and bile duct. Hepatocytes had large vesicular nuclei with acidophilic cytoplasm Fig. (1A,B). H \& E stained sections of CCl4 showed loss of normal hepatic architecture which replaced by different size and shapes cirrhotic nodules surrounded by fibrotic scar with bridging fibrosis extending between portal veins. Some areas showed a picture of marked hepatic fatty degeneration and steatosis. Several hepatocytes revealed shrunken nuclei with deeply acidophilic cytoplasm while other revealed vacuolated cytoplasm. Bile duct proliferation around dilated portal vein was also observed Fig. (1C,D).

In contrast the CCl4-HSC the severity of massive fatty degeneration and liver cirrhosis were markedly decreased. The liver retained its architecture where liver cell becomes more or less similar to normal. However some areas still had distorted architecture Fig. (2A,B). The CCl4fibroblast showed similar picture to $\mathrm{CCl} 4$ group as there was loss of hepatic architecture which replaced by cirrhotic nodules with extensive bridging fibrosis extending between portal veins. Some areas showed fatty degeneration. The hepatocytes revealed shrunken dark stained nuclei with deeply acidophilic cytoplasm Fig. (2C,D).

\section{Masson trichrome staining:}

Examination of liver sections of the control group exhibited few green collagen fibers surround central vein Fig. (3A) and in the portal area Fig. 
(3B) while CCl4 group Fig. (3C,D) showed massive green collagen fibers surrounding cirrhotic nodule, in the bridging fibrosis and around portal veins. Sections of rats treated with CCl4-HSC revealed thin green collagen fibers in portal area and around central vein Fig. (4A,B). While CCl4-fibroblast group Fig. (4C,D) showed massive green collagen fibers surrounding cirrhotic nodule, in the bridging fibrosis and around central veins.

\section{Periodic Acid Schiff reaction (PAS) staining:}

PAS stained sections of the control group showed positive PAS reaction Fig. (5A). The liver tissue of CCl4 Fig. (5B) or CCl4-fibroblast groups Fig. (5D) showed more strongly positive PAS reaction of hepatocyte however fatty cells showed no reaction and weak reaction were observed in the septa. The PAS stained sections of HSC treated group showed moderate positive reaction Fig. (3C).

\section{Immunohistochemical staining of $\alpha$ SMA protein:}

Immunohistochemical stained sections of the control group for $\alpha$ SMA protein expression revealed a weak reaction for $\alpha$ SMA protein Fig. (6A). In the CCl4 Fig. (6B) or CCl4-fibroblast group Fig. (6D), strong positive reaction was detected in numerous cells that present in between the hepatocytes, in portal area and in fibrotic scar. The CCl4-HSC showed a moderate positive $\alpha$ SMA reaction in the lining of portal vein and in few cells that seen in between the hepatocytes Fig. (6).

Characterization of HSCs by $\mathrm{CD} 34^{+}$immunoreactions:

Liver sections of HSC group expressed a CD34 ${ }^{+}$ positive immune reaction in the hepatocytes around portal and central veins Fig. $(7 \mathrm{~A}, \mathrm{~B})$ while liver section from others group (control, CCl4 treated group and $\mathrm{CCl} 4$-fibroblast treated group) showed negative immune reaction in the hepatocytes around central vein and portal vein Fig. (7C,D,E).

\section{Effect of HSC on liver function:}

The results of this study showed marked elevation of levels of liver enzyme, total and direct bilirubin with marked reduction of albumin serumin $\mathrm{CCl} 4$ and CCl4-fibroblast. ANOVA showed highly significant difference between studied group ( $p$ $<0.001$ ) (Table 2). By using least significance difference test, it was recorded a highly significant difference between $\mathrm{CCl} 4$ and $\mathrm{CCl} 4$-fibroblast groups when compared to the CCl4-HSC regarding activities of the liver serum enzymes ALT, AST, and ALP, level of albumin serum and total and direct bilirubin $(p<0.001)$.

\section{Expression of albumin and TGF- $\beta$ genes:}

MRNA expression of albumin and TGF- $\beta$ in hepatocytes showed that the expression level of albumin genes in rats treated with $\mathrm{CCl} 4$ or CCl4fibroblast was significantly lower than those of CCl4-HSC treated groups $(p<0.05)$. While the expression of TGF- $\beta$ gene in $\mathrm{CCl} 4$ or $\mathrm{CCl} 4-$ fibroblast groups was significantly higher than control and CCl4-HSC $(p<0.05)$ (Table 3$)$.

\section{Morphometric results:}

Regarding the morphometrical results of area $\%$ of collagen fibers, area $\%$ of $\alpha$-SMA and optical density of immunoreaction of $\alpha$ SMA revealed a highly significant differences among the studied groups by using ANOVA test ( $p$-value $<0.001$ ). The highest mean was recorded in the $\mathrm{CCl} 4$ group and $\mathrm{CCl} 4$-fibroblast then $\mathrm{CCl} 4 / \mathrm{HSC}$ group while the lowest level was found in the control rats. LSD showed a highly statistical significant difference between the $\mathrm{CCl} 4$ or CCl4-fibroblast and control or CCl4-HSC groups ( $p$-value $<0.001$ ). No significant difference was found between the control and CCl4-HSC groups for the same parameter $(p>0.05)$ (Table 4) Charts $(1,2)$.

Table (2): Liver function assessment in the studied rat groups.

\begin{tabular}{lllllll}
\hline Studied groups & ALT U/L & AST U/L & ALP U/L & $\begin{array}{c}\text { Albumin } \\
\text { gm/dL }\end{array}$ & $\begin{array}{c}\text { Total bilirubin } \\
\mathrm{mg} / \mathrm{dL}\end{array}$ & $\begin{array}{c}\text { Direct bilirubin } \\
\mathrm{mg} / \mathrm{dL}\end{array}$ \\
\hline Control & $32.1 \pm 1.26$ & $117.1 \pm 3.11$ & $124.4 \pm 12.2$ & $3.6 \pm 0.2$ & $0.73 \pm 0.04$ & $0.35 \pm 0.42$ \\
CCl4 & $78.3 \pm 3.31$ & $268.4 \pm 68.40$ & $335 \pm 31$ & $2.5 \pm 0.32$ & $2.98 \pm 0.6$ & $1.2 \pm 0.5$ \\
CCl4-HSC & $35.2 \pm 9.14$ & $129.2 \pm 16.27$ & $142.6 \pm 21.4$ & $3.3 \pm 0.15$ & $1.11 \pm 0.15$ & $0.27 \pm 0.3$ \\
CCl4-Fibroblast & $75.8 \pm 2.35$ & $265.6 \pm 65.31$ & $333 \pm 29$ & $2.2 \pm 0.31$ & $2.7 \pm 0.6$ & $1.1 \pm 0.3$ \\
F & 90.31 & 21.13 & 115.6 & 18.1 & 40.3 & $\mathrm{~K}=4.51$ \\
$p$ & $0.04 *(\mathrm{~S})$ & $0.00 * *(\mathrm{HS})$ & $0.00 * *(\mathrm{HS})$ & $0.00 * *(\mathrm{HS})$ & $0.00 * *(\mathrm{HS})$ & $0.03 *(\mathrm{~s})$ \\
\hline
\end{tabular}

Statistical significant difference $* p<.05$.

**HS: Highly Significant.

$\mathrm{K}:$ Krusskalwallis test F-test for ANOVA. 

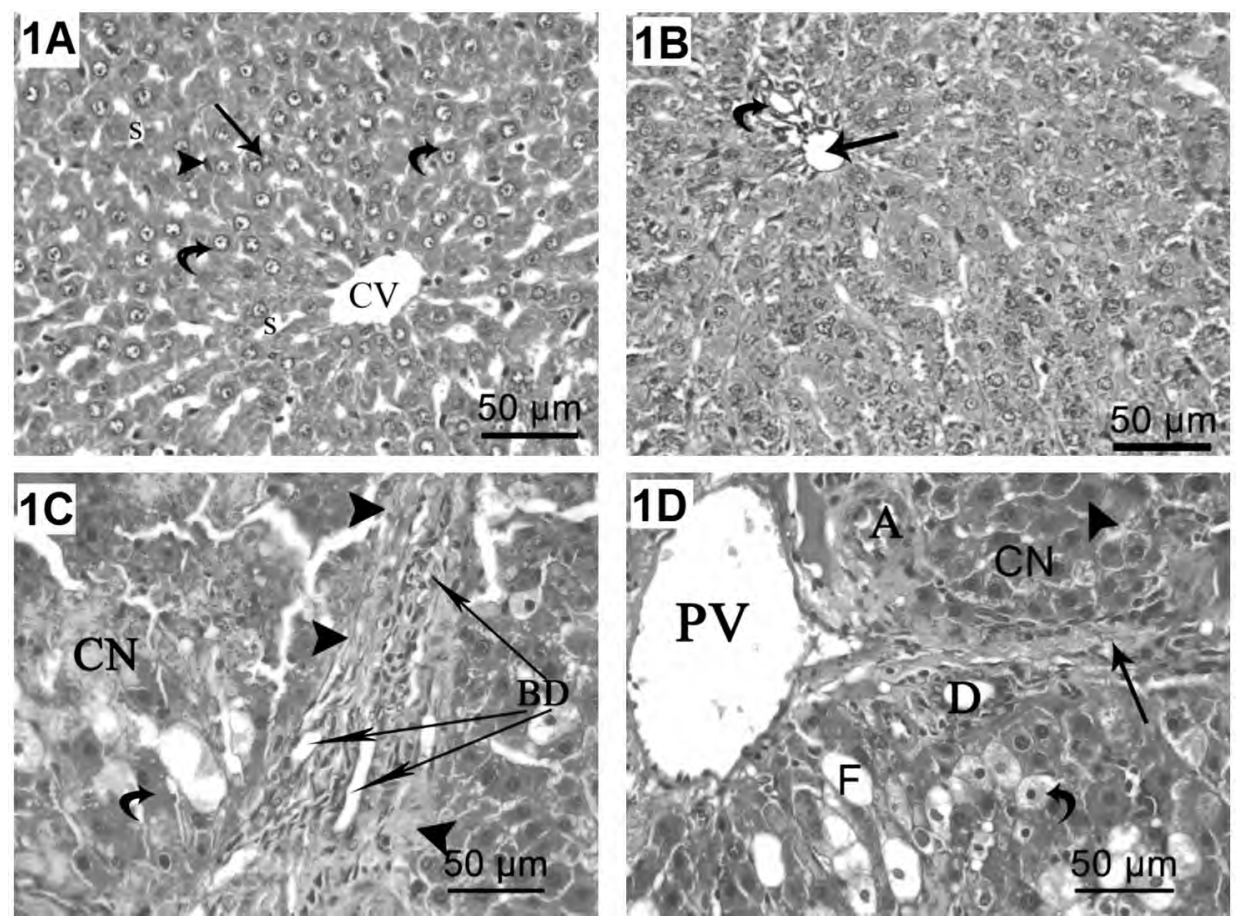

Fig. (1): (A) A photomicrograph of control liver rats shows normal arrangement of hepatic cords around Central Vein (CV), hepatocytes appear with rounded vesicular nuclei with acidophilic cytoplasm (curved arrow), hepatic sinusoids appear between the hepatic cords(S) with its lining epithelium (arrow head) and binucleated cells also appeared (arrow). (B): A photomicrograph of control liver rats shows portal vein (arrow) and bile duct (curved arrow) at the portal area. (C): A photomicrograph of CCl4 treated rats shows formation of Cirrhotic Nodules (CN) which contain hepatocytes that revealed shrunken nuclei with deeply acidophilic cytoplasm (curved arrow) and surrounded by fibrotic scar (arrow head) with bile duct proliferation (arrow). (D): A photomicrograph of CCl4 treated rats shows (H \& E at magnification X400, Bar 50).
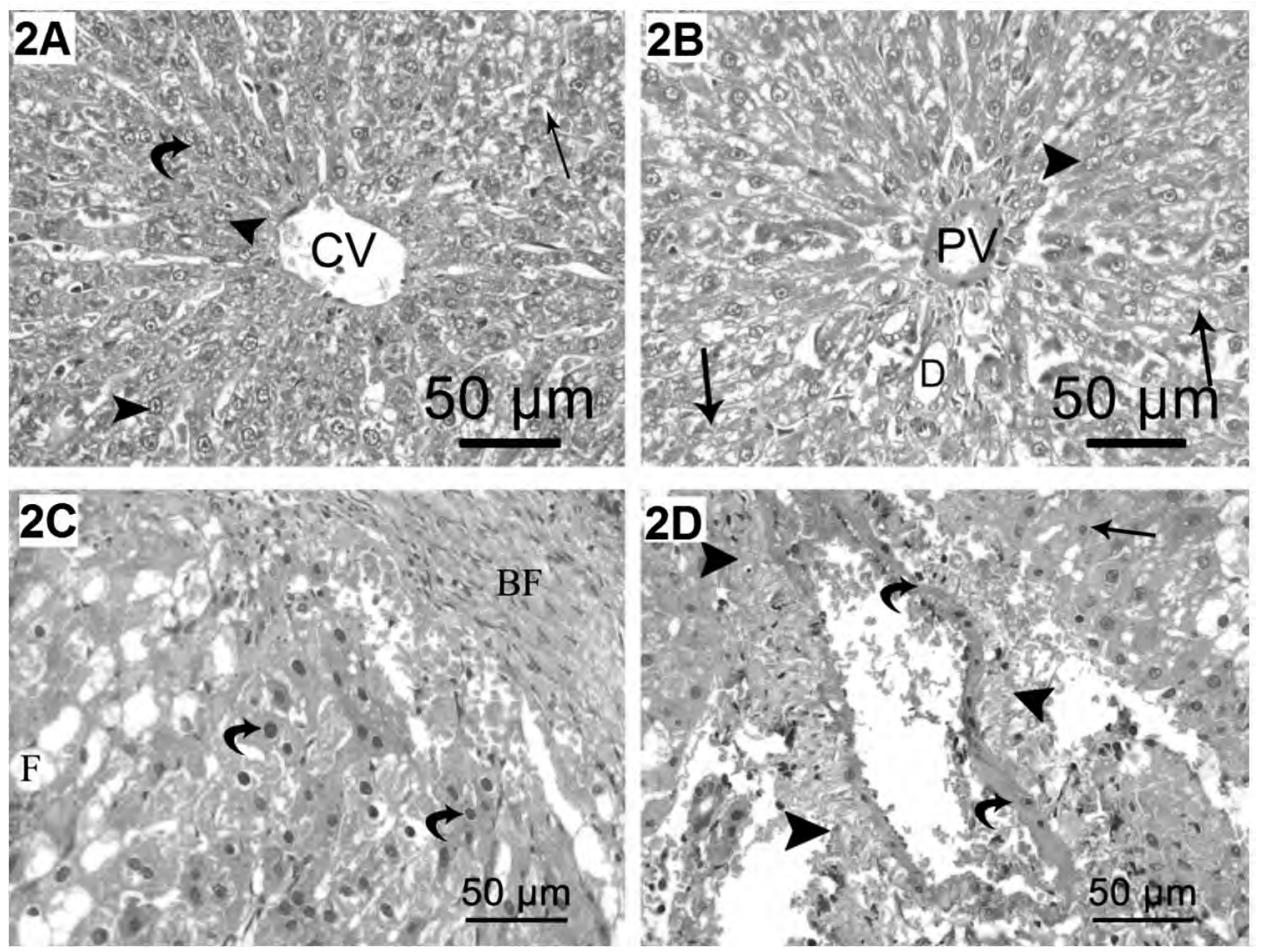

Fig. (2): (A) A photomicrograph of CCl4/HSC treated rats showing nearly normal arrangement of hepatocytes around Central Vein (CV), the hepatocytes appear with rounded vesicular nuclei with acidophilic cytoplasm (arrow head), some hepatocyte with vacuolated cytoplasm also noticed (arrow) while some hepatocyte are binucleated cells (curved arrow). (B): A photomicrograph of CCl4/HSC treated rats showing portal area containing Portal Vein (PV) and bile duct (D). Hepatocytes appear with rounded vesicular nuclei with acidophilic cytoplasm (arrow head), some hepatocyte revealed vacuolated cytoplasm also seen (arrows). (C): A photomicrograph of CCl4 treated rats shows formation of cirrhotic nodules which contain some hepatocytes with fatty degeneration (F) and others revealed shrunken nuclei with deeply acidophilic cytoplasm (curved arrow) and surrounded by Bridging Fibrotic scar (BF). (D): A photomicrograph of CCl4/fibrobl ast treated rats shows thick walled portal vein (curved arrow) inside the fibrotic scar (arrow heads) the hepatocytes which revealed shrunken nuclei with deeply acidophilic cytoplasm (arrow) (H \& E at magnification X400, Bar 50). 

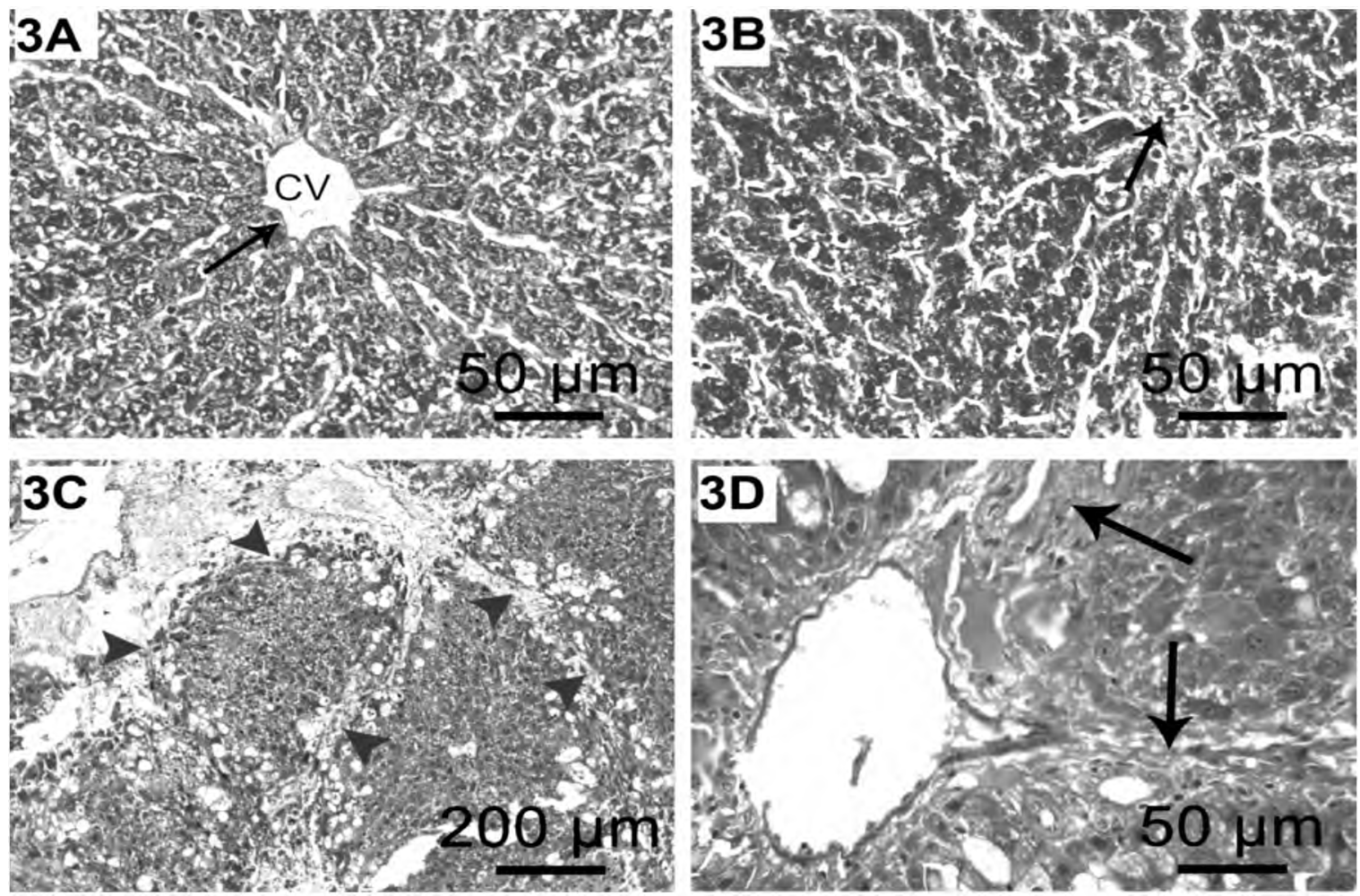

Fig. (3): (A) A photomicrograph of control liver rats shows few amount of collagen fibers (arrow) around (CV). (B): A photomicrograph of control liver rats shows few amount of collagen fibers around portal vein (arrow). (C,D): A photomicrograph of CCl4 treated rats shows formation of collagen fibers around cirrhotic nodules (arrow heads) and excessive amount of green stained collagen fibers around portal vein (arrow) (A, B, D at magnification X400, Bar 50, C at magnification X100, Bar 200) (Masson trichrome).
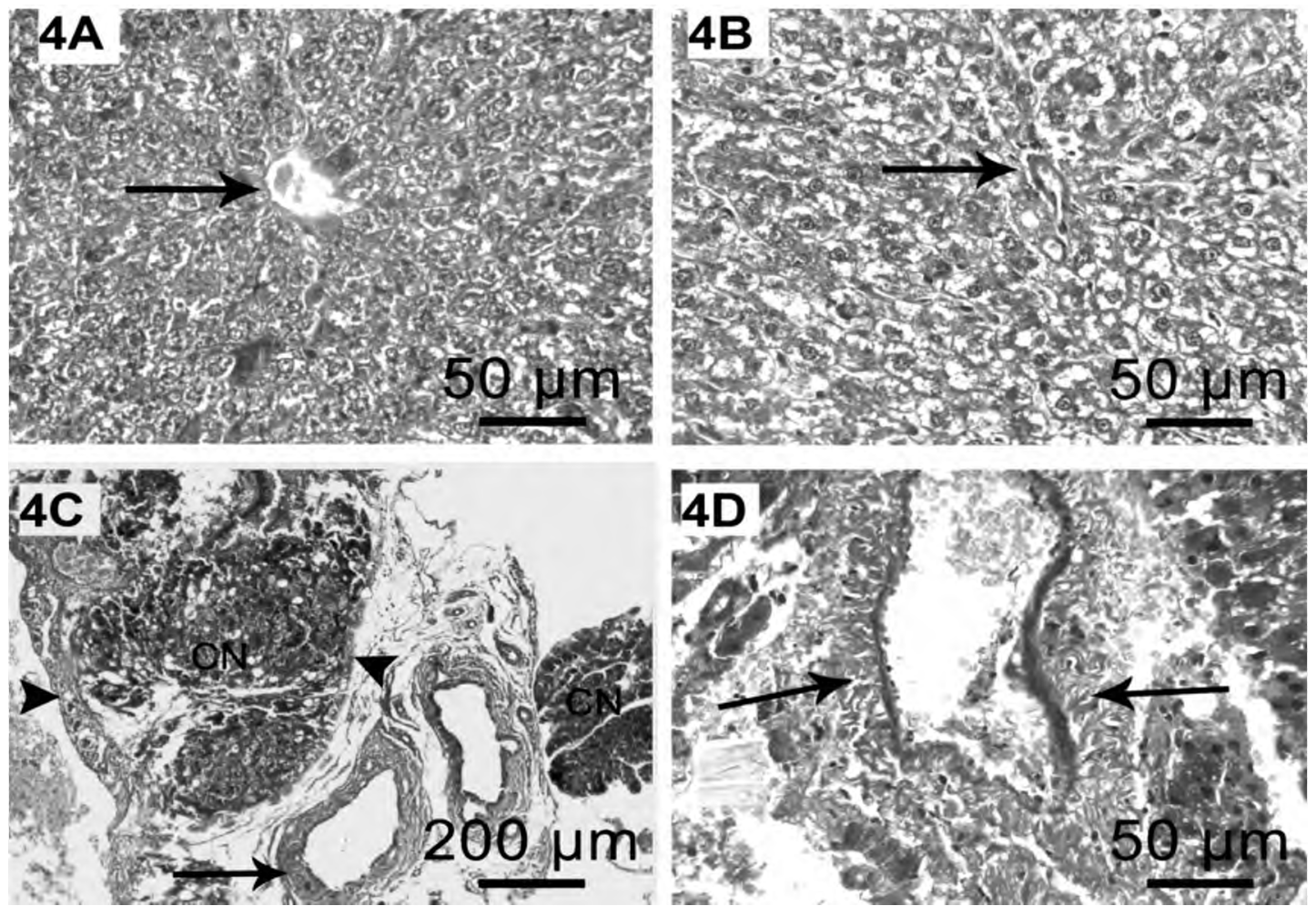

Fig. (4): (A) A photomicrograph of CCl4-HSC treated rats showing few amount of collagen fibers around central vein. (B): A photomicrograph of CCl4-HSC treated rats showing few amount of collagen fibers in the portal area. (C): A photomicrograph of CCL4/fibroblast treated rats shows excessive amount of collagen fibers (arrow heads) around the Cirrhotic nodules (CN) and around blood vessels (arrows). (D): A photomicrograph of CCL4/fibroblast treated rats shows excessive amount of collagen fibers around the portal vein (A, B, D at magnification X400, Bar 50, C at magnification X100, Bar 200) (Masson trichrome). 

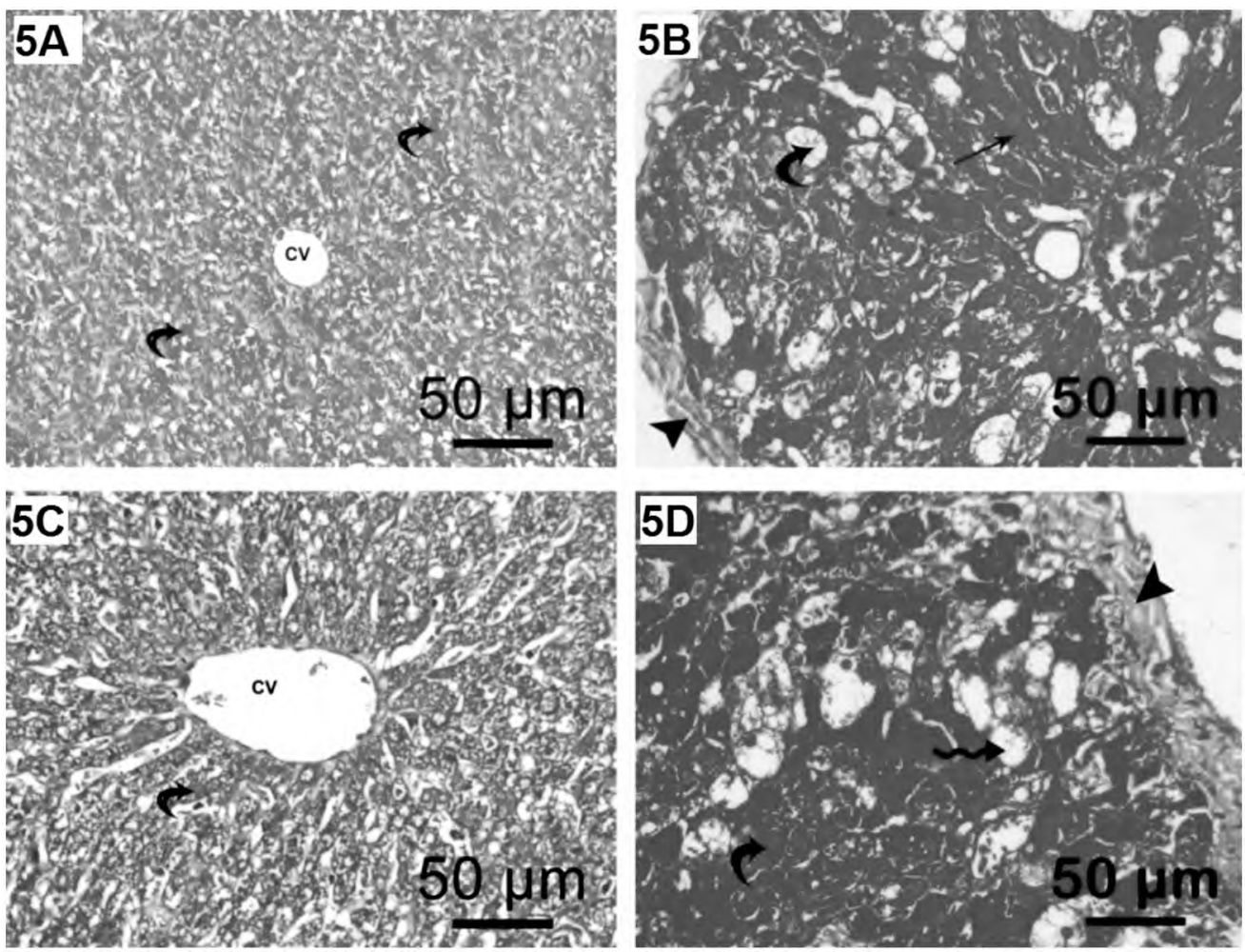

Fig. (5): (A) A photomicrograph of PAS stained sections of the control group showed positive PAS reaction in the hepatocytes (curved arrow) around the Central Vein (CV) (PAS X400). (B): A photomicrograph of PAS stained sections of the liver tissue of CCL4 treated group showed very strong positive PAS reaction inside the hepatocytes (arrow) while other cells with fatty degeneration showed no reaction (curved arrow) and weak reaction was observed in the septa (arrow head) (PAS X400). (C) The PAS stained sections of CCl4-HSC treated group showed moderate positive reaction in the hepatocytes (curved arrow) around the (CV) (PAS X400). (D): A photomicrograph of PAS stained sections of the liver tissue of CCL4/fibrobl ast treated group showed very strong positive PAS reaction inside the hepatocytes (curved arrow) while other cells with fatty degeneration showed no reaction (zigzag arrow) and weak reaction was observed in the septa (arrow head) (PAS X400).
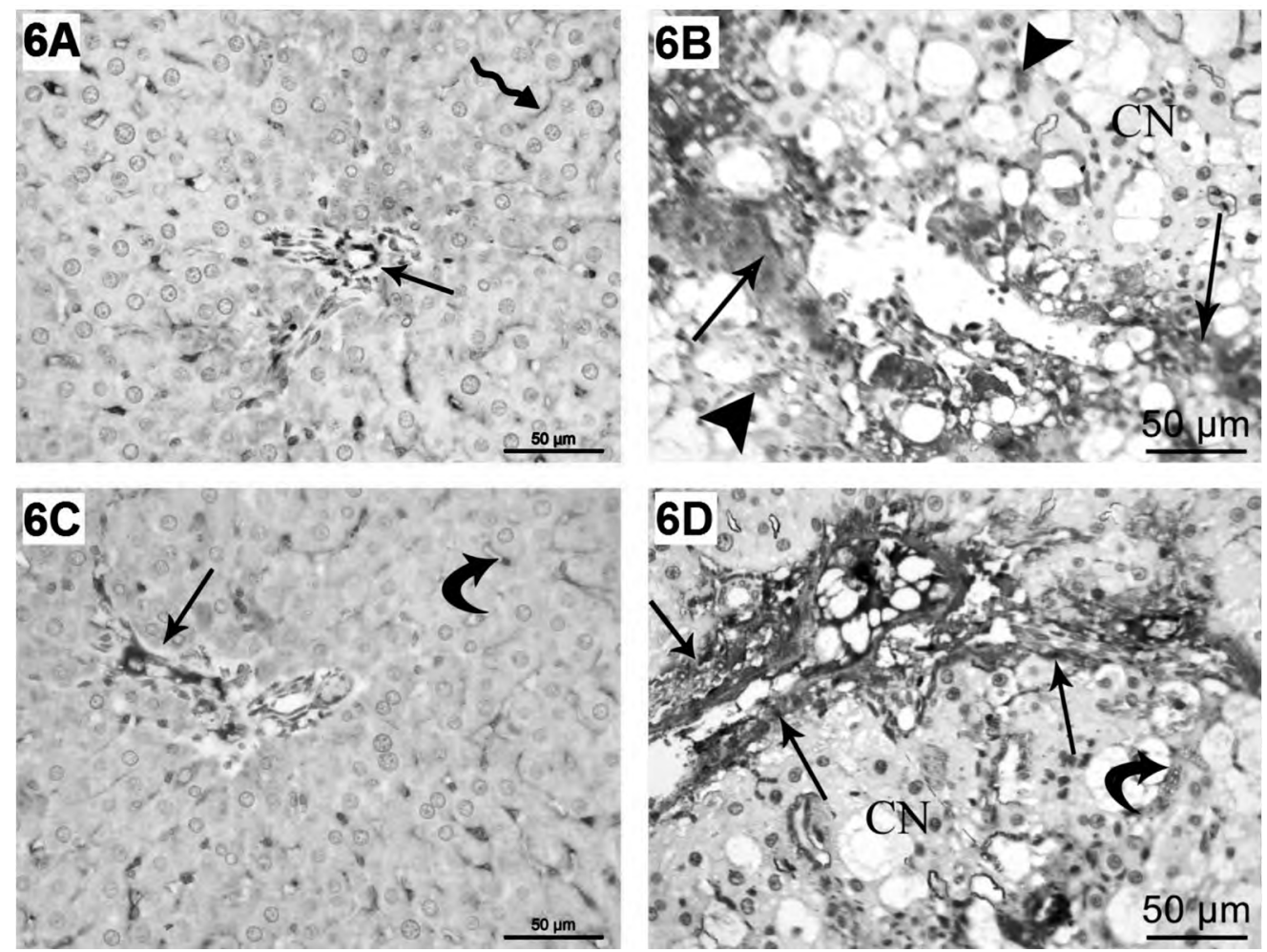

Fig. (6): (A) A photomicrograph of control rats showing weak positive immunreaction in the portal area (arrow) and in lining of the sinusoid (zigzag arrow). (B): A photomicrograph of $\mathrm{CCl} 4$ treated group showing strong positive immunreaction in the portal area (arrow) and between hepatocytes (arrow head). (C): A photomicrograph of CCl4-HSC treated rats showing moderate positive immunreaction in few cells between the hepatocytes (curved arrow) and in the portal area (arrow). (D): A photomicrograph of CCl4/fibroblast treated group showing strong positive immunreaction in the portal area (arrow) wall of sinusoids (curved arrow) (immunoperoxidase technique for $\alpha$-smooth muscle actin X400, bar 50). 

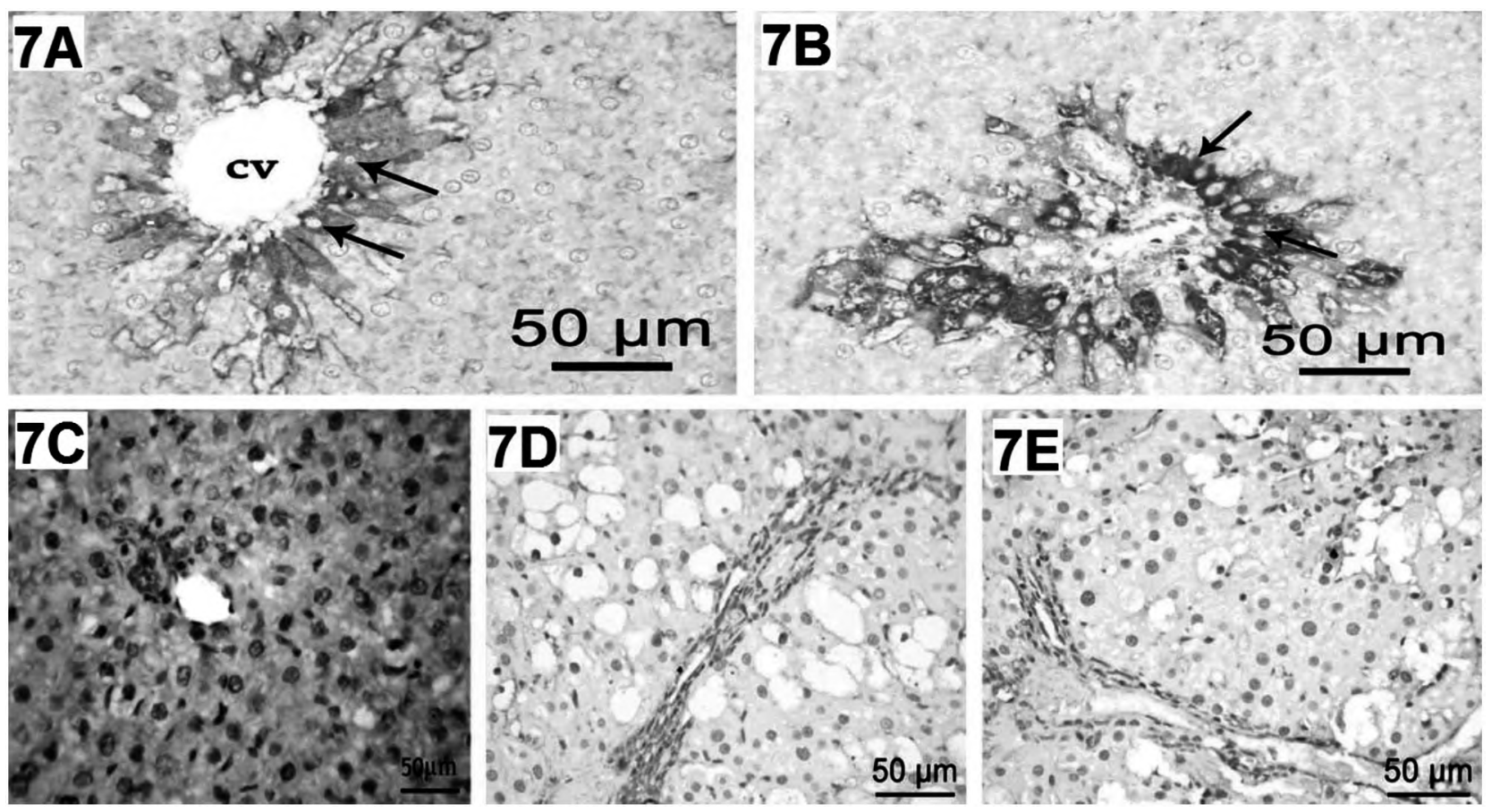

Fig. (7): (A,B) A photomicrograph of $\mathrm{CD} 34^{+}$immunohistochemical stained sections of stem cells treated group showing strong positive expression of $\mathrm{CD} 34^{+}$stem cells in the hepatocytes around central vein (A) and in the hepatocytes around portal vein (B) (immunoperoxidase technique for $\left.\mathrm{CD} 34^{+} \mathrm{X} 400\right)$. (C, D, E): A photomicrograph of CD34 ${ }^{+}$immunohistochemical stained sections of control, CCL4 and CCL4/ fibroblast treated group showing negative expression of $\mathrm{CD} 34^{+}$stem cells in the hepatocytes around central vein and portal area (immunoperoxidase technique for $\left.\mathrm{CD} 34^{+} \mathrm{X} 400\right)$.

Table (3): Gene expression of albumin and TGF- $\beta$ genes between different studied groups.

\begin{tabular}{lll}
\hline Studied groups & Albumin & TGF- $\beta$ \\
\hline Control & $3.83 \pm 0.68$ & $0.20 \pm 0.06$ \\
CCl4 & $0.87 \pm 0.24$ & $1.03 \pm 0.28$ \\
CCl4-HSC & $2.61 \pm 0.71$ & $0.58 \pm 0.18$ \\
CCl4-Fibroblast & $0.81 \pm 0.25$ & $1.01 \pm 0.31$ \\
F & 45.129 & 19.430 \\
$p$ & $0.00^{* *}$ & $0.00^{* *}$ \\
\hline
\end{tabular}

Table (4): The area $\%$ of collagen fibers, area $\%$ of $\alpha$ smooth muscle actin and optical density $\alpha$ smooth muscle actin in different groups.

\begin{tabular}{llll}
\hline & $\begin{array}{c}\text { Area \% of } \\
\text { collagen fibers }\end{array}$ & $\begin{array}{c}\text { Area \% of } \\
\alpha \text { smooth } \\
\text { muscle actin }\end{array}$ & $\begin{array}{c}\text { Optical density } \\
\text { of } \alpha \text { smooth } \\
\text { muscle actin }\end{array}$ \\
\hline Control & $1.03 \pm 0.4$ & $1.34 \pm 1.1$ & $0.8 \pm 0.16$ \\
CCl4 & $27.6 \pm 11.3$ & $21.2 \pm 2.2$ & $2.84 \pm 0.56$ \\
CCl4-HSC & $10.1 \pm 3.2$ & $2.6 \pm 1.62$ & $1.83 \pm 0.5$ \\
CC14-Fibroblast & $25.5 \pm 10.4$ & $20.4 \pm 2.0$ & $2.63 \pm 0.5$ \\
F & 16.5 & 240.6 & 33.23 \\
$p$ & $0.000^{* *}$ & $0.000 * *$ & $0.000 * *$ \\
\hline
\end{tabular}

$*$ : Significant $(p<0.05)$.

$* *$ : Highly significant $(p<0.001)$

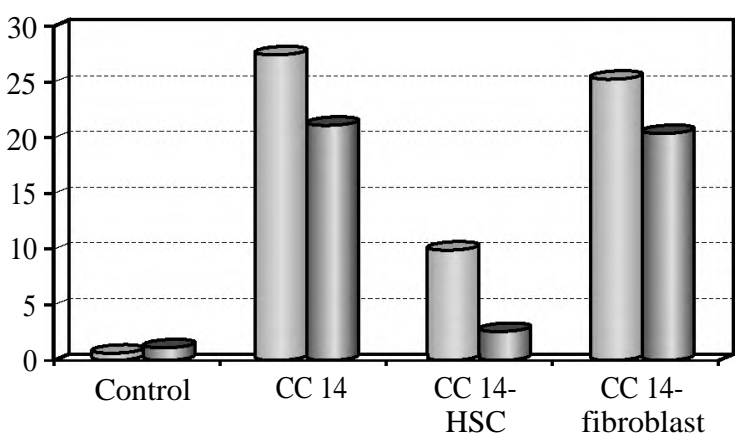

$\square$ Area $\%$ of collagen fibers
$\square$ Area $\%$ of smooth muscle actin

Chart (1): The area $\%$ of $\alpha$ smooth muscle actin and collagen fibers in the different studied groups.

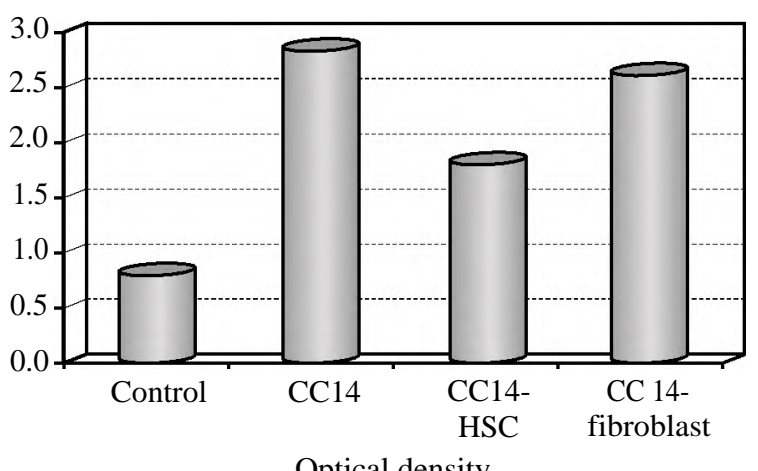

Chart (2): The optical density of immune reaction to $\alpha$-smooth muscle actin in the different studied groups. 


\section{Discussion}

The liver transplantation is considered as most beneficial treatment for patients who suffering from chronic liver diseases. However, for many patients it is difficult to have transplantation due to unavailable donor livers and about $10 \%$ of the patients while they are waiting transplantation they die. The survival rate in patients who had received liver transplantation was $93 \%$ in the first 3 months, $85 \%$ at the first year and $78 \%$ at 3 years [21].

Hematopoietic stem cells as the chief population of bone marrow stem cells, were expressing its own surface marker CD34 +. HSCs had the ability to move away from the bone marrow and circulate into the blood. Their mobilization depended on easily substances released during tissue injury particularly Granulocyte-colony stimulating factor [22]. They were self-renewable that can be differentiated into progenitor cells [23]. CD34+ peripheral blood stem cells had exhibited a great effect on experimental animal models of liver disease and voluntaries patients who suffering from chronic hepatic diseases $[\mathbf{1 9 , 2 1 , 2 4 ]}$. So this study was designed to investigate if hematoipoietic stem cells have the capability to retain the hepatic structure in experimental rat model of liver cirrhosis.

In the current work, Carbon tetrachloride (CC14) was used to induce experimentally cirrhosis in rat liver as the CC14 model was the most one that resemble cirrhosis of human liver [25].

In the present study, the $\mathrm{H} \& \mathrm{E}$ stained sections of control livers revealed classic characteristic appearance of hepatic lobules which consisted of cords of hepatocyte radiating from central vein. Portal area is present at the corner of lobule containing branches of portal vein, hepatic artery and bile duct. Hepatocytes had large vesicular nuclei with acidophilic cytoplasm. Some binucleated hepatocytes were noticed. Blood sinusoids which lined by endothelial cells and Kupffer cells were noticed between cords of hepatocytes and These results were in agreement with [26,27].

In the this study, livers of $\mathrm{CCl} 4$ treated group indicated loss of normal hepatic architecture which replaced by different size and shapes cirrhotic nodules with bridging fibrosis extending between central and portal veins. Haemosiderin engulfing cells were observed. These results were in accordance with $[28,29]$.

In the CCl4-HSC treated group, there were remarkable improvement as the severity of massive fatty degeneration and liver cirrhosis was markedly decreased and the liver retained its architecture and liver cell becomes more or less similar to normal. However some areas still had distorted architecture. The CCl4-fibroblast showed similar picture to $\mathrm{CCl} 4$ group [30]

It was reported that hematopoietic stem cells not only had the ability of homing to specific damaged tissues, but also capability of differentiation and stimulation of local repair response [31] Two mechanisms were involved in liver regeneration by Hematopoietic stem cells; the first one is the self-generation of hepatocytes by transdifferentiation and the second is the genetic programming of the resident hepatocytes by cell fusion [30].

Masson Trichrome stained sections of the control group revealed minimal amount of collagen fibers around the central vein and in the portal area. These findings were in agreement with [32], but the Masson Trichrome stained sections of CCl4 group revealed extensive collagen fibers in bridging fibrosis, the portal area and the around central vein. These results are proved morphmetrically by significant increase of area percentage of collagen fibers in $\mathrm{CCl} 4$ treated groups.

Yang et al., [33] explained that increased collagen fibers were due to oxidative stress produced by $\mathrm{CCl} 4$. Moreover $[33,34]$ mentioned that damaged hepatocyte promoted the activation of Kupffer cells with subsequent production of growth factor and cytokines which promoted transformation of the hepatic satellite cells into myofibroblasts like cells. These myo-fibroblasts like cells had the capability of depositing huge amounts of the main components connective tissue like collagen and adhesive glycoproteins.

Administration of $\mathrm{HSC}$ to $\mathrm{CCl} 4$ treated rat resulted in massive reduction of collagen fibers as monitored by Masson trichrome stained section and proved by morphmetrically calculation of area percent of collagen fibers. HSCs were not only considered as the primary source of new regenerated hepatocytes but also their actions were associated markedly with macrophages, that gave rise to a series of collagenases that facilitated the process of liver regeneration [35].

In control and HSC groups, there were positive PAS reaction that can explained by that normal hepatocytes had considerable amount of glycogen these results were in accordance with results of [36]. Moreover, the CCl4 treated and CCl4/ fibroblast treated groups exhibited more positive PAS reaction and these results were agreed by [44] who 
explained that regenerated cirrhotic nodule contain huge glycogen granules.

In $\mathrm{CCl} 4$ or $\mathrm{CCl} 4 /$ fibroblast treated groups revealed increased positivity of $\alpha$-SMA immunoreactions as detected morphometrically by significant increased area percent and optical density of $\alpha$ SMA positive cells. These results passed in parallel line with increased collagen level as monitored morphometrically by increased area percent of collagen fiber in Masson trichrome section. $\alpha$ SMA was taken as a real marker for the hepatic satellite cells activity which were known as the primary cell that caused fibrogenesis [37].

There was positive immunoreaction for CD34 + cells in the HSC group that appeared in hepatocytes around central vein and in portal area. This was due to differentiation of CD34 + cells around the hepatocytes of vascular area. These results were matched with other studies [19] but there was negative immunoreaction for CD34+ cells in other groups of this study.

Liver dysfunction was obvious in both $\mathrm{CCl} 4$ or CCl4-fibroblast treated groups. As there were significant elevation of serum levels of ALT, AST and ALP and a marked reduction of albumin level. These results are in accordance with Zaho et al., [39] who detected liver dysfunction in rat after induction of liver fibrosis by $\mathrm{CCl} 4$, also they observed absence of recovery after $\mathrm{CCl} 4$ withdrawal [38]. Explained that marked increase of ALT, AST, ALP, direct and total bilirubin in addition to reduction albumin levels is due to liver inflammation with subsequent edema of the organelles and structural damage [39].

In the present study, there were non-remarkable changes seen in liver biochemical tests including albumin, bilirubin, ALP, ALT and AST levels in HSC group versus the control group. It was reported that transplanted CD34 + HSC had the ability to restore the serum albumin and bilirubin level and markedly decrease the strength of liver cirrhosis and fibrosis in a rat model of injured liver [30,40]

In the present study there is increased expression of TGF- $\beta$ gene in $\mathrm{CCl} 4$ or CCl4-fibroblast groups. Several studies focused on the role of TGF- $\beta$ expression in vascular endothelial cells for endoglin production. Endoglin which was known as the main expressed profibrogenic cytokines that had vital role in transdifferentiation of satellite cells to myofibroblasts like cells. This also can recognized by $\alpha$-SMA immunoreactions $[41,42]$.
Improvement of cirrhotic liver after HSC treatment was proved also by increase expression of albumin gene and by decreased expression of TGF$\beta$ gene. This is may be due to resolution of cirrhosis and repairing of the diseased hepatocytes [43]. Gene expression results added supportive evidence for biochemical, histological, immunohistochemical and morphometrical results. These results provided a new hope for ameliorating liver cirrhosis by instead of liver transplantation as traditional treatment with its common complications.

\section{References}

1- BERARDIS S., SATTWIKA P., NAJIMI M. and SOKA E.: Use of mesenchymal stem cells to treat liver fibrosis: Current situation and future prospects. World J. Gastroenterol., 21 (3): 742-58, 2015.

2- SCHUPPAN D. and AFDHAL N.: Liver cirrhosis. The Lancet, 371 (9615): 838-51, 2008.

3- BASTO S., RIBEIRO J. and PEREZ R.: Liver transplantation waiting list mortality and its characteristics in a Brazilian center. Liver Transplantation, 13: 177, 2007.

4- ZHAO Q., REN H., ZHU D. and HAN Z.: Stem/progenitor cells in liver injury repairand regeneration. Biol. Cell, 101: 557-71, 2009.

5- OGAWA S. and MIYAGAWA S.: Potentials of regenerative medicine for liver disease. Surg. Today, 39: 101925, 2009.

6- THOMSON J., ITSKOVITZ-ELDOR J., SHAPIRO S., WAKNITZ M., SWIERGIEL J. and MARSHALL V.: Embryonic stem cell lines derived from human blastocysts. Science, 282: 1145-7, 1998.

7- PITTENGER M., MACKAY A., BECK S., JAISWAL R., DOUGLAS R. and MOSCA J.: Multilineage potential of adult human mesenchymal stem cells. Science, 284: 143-7, 1999.

8- McINTOSH K., ZVONIC S., GARRETT S., MITCHELL J., FLOYD Z. and HAMMILL L.: The immunogenicity of human adipose-derived cells: Temporal changes in vitro. Stem Cells, 24: 1246-53, 2006.

9- BARRY FAND MURPHY J.: Hematopioetic stem cells: Clinical applications and biological characterization. Int. J. Biochem. Cell Biol., 36: 568-84, 2004.

10- SATO Y., ARAKI H., KATO J., NAKAMURA K., KAWANO Y., KOBUNE M., SATO T., et al.: Human stem cells xenografted directly to rat liver are differentiated into human hepatocytes without fusion. Blood, 106: 75663, 2005.

11-FUJI T., FUCHS B., YAMADA S., LAUWERS G., KULU Y., GOODWIN J., et al.: Mouse model of carbon tetrachloride induced liver fibrosis: Histopathological changes and expression of CD133 and epidermal growth factor. BMC Gastroenterol., 10: 79, 2010.

12- ABDEL AZIZ M., ATTA H., ROSHDY N., RASHED L., SABRY D., HASSOUNA A., et al.: Amelioration of murine schistosoma mansoni induced liver fibrosis by mesenchymal stem cells. J. Stem Cells Regen., 8: 28-34, 2012. 
13- Di CAMPLI C., PISCAGLIA A., PIERELLI L., et al.: A human umblical cord stem cell rescue therapy in a murine model of toxic liver injury. Dig. Liver. Dis., 36: 603-13, 2004.

14- NAKAMURA T., TORIMURA T., SAKAMOTO M., HASHIMOTO O., TANIGUCHI E. and INOUE K.: Significance and therapeutic potential of endothelial progenitor cell transplantation in a cirrhotic liver rat model. Gastroenterology, 133: 91-107, 2007.

15- BANCROFT J. and GAMBLE A.: Theory and Practice of Histological Techniques. $6^{\text {th }}$ ed. Churchill Livingstone, New York, London: 165-75, 2008.

16- RAMOS-VARA J., KIUPEL M., BASZIER T., BLIVEN L., BRODERSEN B., CHELACK B., et al.: Suggested guide lines for immunohistochemical techniques in veterinary diagnostic laboratories. J. Vet. Diagn. Invest., 20: 393-413, 2008

17- TIETZ N.: Clinical Guide to Laboratory Tests. WBS aunders Company, Philadelphia, PA: 518-22, 1995.

18- YOSHIDA K., ONO M., MAEJIMA T., ESAKI M. and SAWADA H.: Oligo potent mesenchymal stem cell-like clone becomes multinucleated following phorbol ester, TPA stimulation. Anat. Rec., 120: 1256-67, 2007.

19-NAKAMURA T., TORIMURA T., IWAMOTO H., KUROGI J., INOUE H., HORI Y., et al.: CD34 ${ }^{+}$cell therapy is safe and effective in slowing the decline of hepatic reserve function in patients with decompensated liver cirrhosis. J. Gastroenterol. Hepatol., 29: 1830-38, 2014.

20- DEAN A., DEAN G. and COLMBIER D.: Epi-Info Version for the Year 2000. Data Base, Statistics and Epidemiology on Microcomputer CDC, Georgia, USA, 2000.

21- FREEMAN J., STEFfiCK D., GUIDINGER M., FARMER D., BERG C. and MERION R.: Liver and intestine transplantation in the United States, 1977-2006. Am. J. Transplant., 8 (2): 958-76, 2008.

22- TSOLAKI E. and YANNAKI E.: Stem cell-based regenerative opportunities for the liver: State of the art and beyond. World Journal of Gastroenterology, 21 (43): 12334-50, 2015.

23- HOMBACH-KLONISCH S., PANIGRAHI S., RASHEDI I., et al.: Adult stem cells and their trans-differentiation potential-Perspectives and therapeutic applications. Journal of Molecular Medicine, 86 (12): 1301-14, 2008.

24- SALAMA H., ZEKRI A., ZERN M., BAHNASSY A., LOUTFY S., SHALABY S., et al.: Autologous hematopoietic stem cell transplantation in 48 patients with endstage chronic liver diseases. Cell Transplant., 19: 1475$86,2010$.

25- GEERTS A., VANHEULE E., PRAET M., VAN VLIERBERGHE H., De VOS M. and COLLE I.: Comparison of three research models of portal hypertension in mice: Macroscopic, histological and portal pressure evaluation. Int. J. Exp. Pathol., 89: 251-63, 2008.

26- APTE U., ZENG G., THOMPSON M., MULLER P., MICSENYI A., CIEPLY B., KAESTNER K. and MONGA S.: Beta-Catenin is critical for early postnatal liver growth. Am. J. Physiol. Gastrointest. Liver Physiol., 292: 1578$85,2007$.
27- BARATTA J., NGO A., LOPEZ B., KASABWALLA N., LONGMUIR K. and ROBERTSON R.: Cellular Organization of Normal Mouse Liver: A Histological, Quantitative Immunocytochemical and Fine Structural Analysis. Histochem. Cell Biol., 131 (6): 713-26, 2009.

28- ZHAO W., LI J., CAO D., ZHANG L., HE Y., YUE S., et al.: Intravenous injection of mesenchymal stem cells is effective in treating liver fibrosis. World J. Gastroenterol., 8 (10): 1048-58, 2012.

29- PAREZ T.: Is cirrhosis of the liver experimentally produced by $\mathrm{CCl} 4$ an adequate model of human cirrhosis? Hepatology, 3: 112-20, 1983.

30- VAINSHTEIN J., KABARRITI R., MEHTA K., ROYCHOWDHURY J. and GUHA C.: Bonemarrow-derived stromal cell therapy in cirrhosis: Clinical evidence, cellular mechanisms, and implications for the treatment of Hepatocellular carcinoma. International Journal of Radiation Oncology, Biology and Physics, 89 (4): 786-803, 2014.

31- WAGERS A. and WEISSMAN I.: Plasticity of adult stem cells. Cell, 116: 639-48, 2004

32- ALSHAWSH M., ABDULLA M., ISMAIL S. and AMIN Z.: Hepatoprotective effects of Orthosiphonstamineus extract on thioacetamide-induced liver cirrhosis in rats. Evid. Based Complement Altern. Med., 2011: 103039, 2011.

33- YANG F., FANG B. and LOU J.: Effects of HaobieYangy in Ruanji and ecoction on hepatic fibrosis induced by carbon tetrachloride in rats. World J. Gastroenterol., 16: 1458-64, 2010

34- SENOO H., YOSHIKAWA K., MORII M., MIURA M. IMAI K. and MEZAKI Y.: Hepatic stellate cell (Vitamin A-storing cell) and its relative-past, present and future. Cell Biol. Int., 34: 1247-72, 2010.

35- BOULTER L., GOVAERE O., BIRD T., et al.: Macrophage-derived Wnt opposes Notch signaling to specify hepatic progenitor cell fate in chronic liver disease. Nature Medicine, 18 (4): 572-9, 2012.

36- ABU-DIEF E., KHALIL K., ABDEL-AZIZ H., NORELDIN E. and RAGAB E.: Histological Effects of Titanium Dioxide Nanoparticles in Adult Male Albino Rat Liver and Possible Prophylactic Effects of Milk Thistle Seeds. Life Science Journal, 12 (2): 115-23, 2015.

37- CHEUNG P., ZHANG Q., ZHANG Y., BAI G., LIN M. and CHAN B.: Effect of WeiJiaon carbon tetrachloride induced chronic liver injury. World J. Gastroenterol., 12: 1912-17, 2006.

38- TASCI I., MAS N., MAS M., TUNCER M. and COMERT B.: Ultrastructural changes in hepatocytes after taurine treatment in $\mathrm{CCl} 4$ induced liver injury. World J. Gastroenterol., 14: 4897-902, 2008.

39- ZHAO D., LEI J. and CHEN R.: Bone marrow-derived mesenchymal stem cells protect against experimental liver fibrosis in rats. World J. Gastroenterol., 11: 343140, 2005.

40- OYAGI S., HIROSE M., KOJIMA M., OKUYAMA M., KAWASE M. and NAKAMURA T.: Therapeutic effect of transplanting HGF-treated bone marrow mesenchymal cells into CCl4-injured rats. J. Hepatol., 44: 742-8, 2006. 
41- PUCHE J., SAIMAN Y. and FRIEDMAN S.: Hepatic stellate cells and liver fibrosis. Compr. Physiol., 3: 1473 92, 2013.

42- WIERCINSKA E., WICKERT L., DENECKE B., SAID H., HAMZAVI J., GRESSNER A., et al.: Id1 is a critical mediator in TGF-beta-induced transdifferentiation of rat hepatic stellate cells. Hepatology, 43: 1032-41, 2006.

43- GARG V., GARG H., KHAN A., TREHANPATI N.,
KUMAR A., SHARMA B., SAKHUJ P. and SARIN S.: Granulocyte colony-stimulating factor mobilizes CD34(+) cells and improves survival of patients with acute-onchronic liver failure. Gastroenterology, 142: 505-12, 2012.

44- GUERRA R.R.,TROTTA M.R., ALOLA T.P., DAGLI M.L. and HERNANDEZ-BLAZQUEZ F.J.: A novel chronic cirrhosis TAA-induced model in rats. Brazilian Journal of Veterinary Pathology, Vol. 3, N. 1, p. 9-16, 2010.

\section{تآثيرات الخلايا الجذعية الدموية

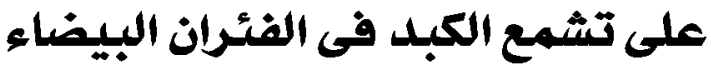

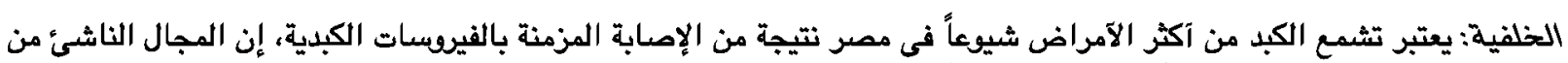

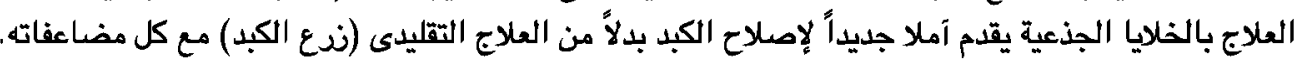

الغرض من البحث: تم تنفيذ هذا العمل بهدف توضيح الإمكانات العلاجية الخلايا الجذعية الدموية في الإصلاح الكبدى كخط جديد من

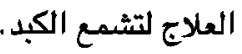

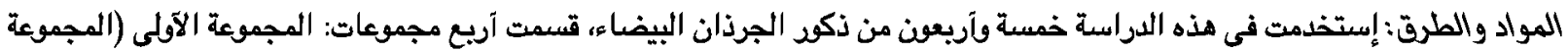

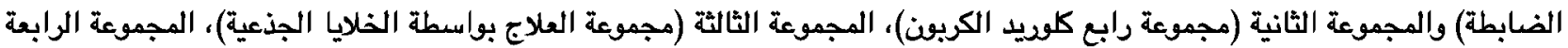

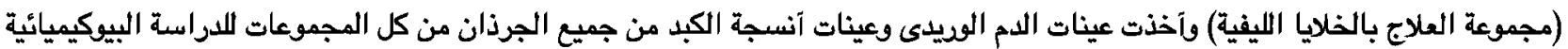

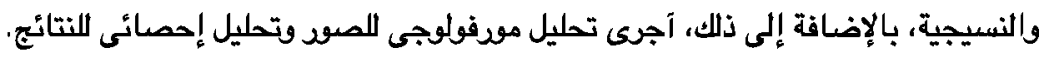

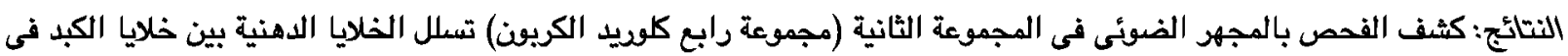

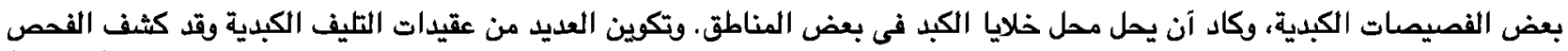

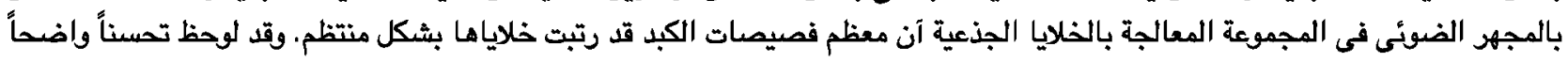

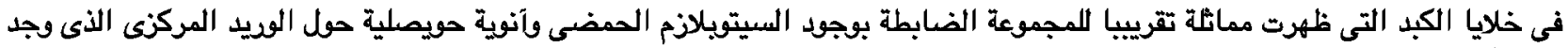

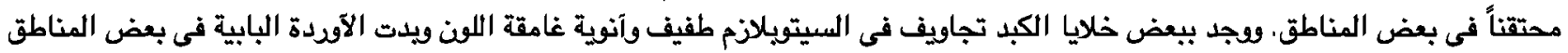

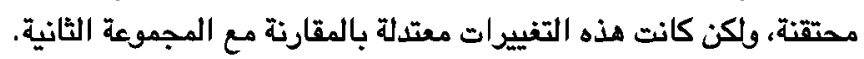

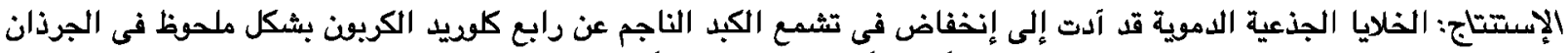

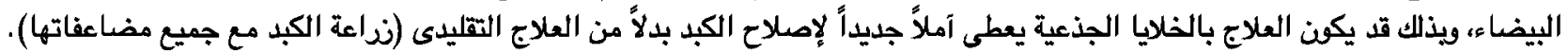

